Article

\title{
A Two-stage Optimal Network Reconfiguration Approach for Minimizing Energy Loss of Distribution Networks Using Particle Swarm Optimization Algorithm
}

\author{
Wei-Tzer Huang 1,*, Tsai-Hsiang Chen ${ }^{2}$, Hong-Ting Chen ${ }^{1}$, Jhih-Siang Yang ${ }^{2}$, Kuo-Lung Lian ${ }^{2}$, \\ Yung-Ruei Chang ${ }^{3}$, Yih-Der Lee ${ }^{3}$ and Yuan-Hsiang $\mathrm{Ho}^{3}$ \\ Received: 7 October 2015; Accepted: 1 December 2015; Published: 5 December 2015 \\ Academic Editor: Neville Watson \\ 1 Department of Industrial Education and Technology, National Changhua University of Education, No. 2, \\ Shida Road, Changhua 500, Taiwan; edchen1991@gmail.com \\ 2 Department of Electrical Engineering, National Taiwan University of Science and Technology, No.43, \\ Section 4, Keelung Road, Da'an District, Taipei City 106, Taiwan; thchen@mail.ntust.edu.tw (T.-H.C.); \\ m10307106@mail.ntust.edu.tw (J.-S.Y.); ryanlian@mail.ntust.edu.tw (K.-L.L.) \\ 3 The Institute of Nuclear Energy Research, 1000 Wenhua Road, Jiaan Village, Longtan District, \\ Taoyuan City 325, Taiwan; raymond@iner.gov.tw (Y.-R.C.); ydlee@iner.gov.tw (Y.-D.L.); \\ twingo_ho@iner.gov.tw (Y.-H.H.) \\ * Correspondence: vichuang@cc.ncue.edu.tw; Tel.: +886-4-723-2105 (ext. 7264); Fax: +886-4-721-1287
}

\begin{abstract}
This study aimed to minimize energy losses in traditional distribution networks and microgrids through a network reconfiguration and phase balancing approach. To address this problem, an algorithm composed of a multi-objective function and operation constraints is proposed. Network connection matrices based on graph theory and the backward/forward sweep method are used to analyze power flow. A minimizing energy loss approach is developed for network reconfiguration and phase balancing, and the particle swarm optimization (PSO) algorithm is adopted to solve this optimal combination problem. The proposed approach is tested on the IEEE 37-bus test system and the first outdoor microgrid test bed established by the Institute of Nuclear Energy Research (INER) in Taiwan. Simulation results demonstrate that the proposed two-stage approach can be applied in network reconfiguration to minimize energy loss.
\end{abstract}

Keywords: energy loss; distribution network; microgrid; network reconfiguration; phase balancing; particle swarm optimization (PSO); connection matrices

\section{Introduction}

The major function of traditional passive distribution networks is to distribute electrical power to customers. Because voltage levels in such networks are relatively lower and their total length is longer compared with transmission networks, reducing power losses in distribution networks is vital; furthermore, the annual energy loss of the power system will be diminished. At present, many distribution energy resources (DERs) are connected to distribution networks. Distribution networks have become active networks called microgrids. Microgrids consist of DERs and loads. DERs include renewable and nonrenewable generation units, as well as storage devices, such as photovoltaic systems, wind turbines, fuel cells, microturbines, diesel engines, battery banks, and supercapacitors, among other [1-3]. Microgrids can be operated under grid-tied and islanding modes through a static switch at the common coupling point between the main power grid and the microgrid [4]. In the grid-tied operation mode, the microgrid may act as a load or source at any time in terms of the main power grid. The islanding operation mode must be operated autonomously based on the power 
balance principle to maintain constant voltage and frequency. Numerous renewable energy units are used in microgrids. Thus, $\mathrm{CO}_{2}$ emissions are reduced and global warming is prevented. Constructing microgrids in industrial parks, campuses, shopping malls, off-shore islands, and remote districts is worthwhile because of the all the aforementioned advantages.

The system planning, designing, operating, and controlling of microgrids is more complex compared with traditional passive distribution systems. Consequently, an energy management system (EMS) is essential in the system operation stage in microgrids [5-7]. To increase operating efficiency, the network reconfiguration and phase balancing approach, which is one of the functions in EMS, has been adopted to minimize power loss and improve voltage quality. Merlin and Back [8] used a spanning tree structure to model a distribution system. The obtained solution results were independent from the initial status of the switches; however, their algorithm was very time-consuming. Civanlar et al. [9] proposed a branch-exchange method to minimize the number of switching operations; however, this approach is not systematic and can only reduce power loss. Jeon et al. [10] presented a simulated annealing algorithm for network reconfiguration; this algorithm was easy to code but required considerable computation time in large-scale systems. Venkatesh and Ranjan [11] proposed an approach that used an evolutionary programming with fuzzy adaptation as a solution technique; however, as a system grew larger, this method became increasingly complex. Hamdoui et al. [12] used the ant colony approach algorithm to identify the optimal combination of feeders with different natures to find a new network topology. This method is highly efficient and convergence definitely occurs; however, the length of time required to achieve convergence remains uncertain.

In this work, a population-based stochastic optimization technique that adopts the particle swarm optimization (PSO) algorithm is used to search for the solutions of the proposed two-stage approach, which is to solve the optimal network reconfiguration at the first stage and phase balancing at second stage. This paper is divided into four sections: Section 1 presents the introduction; Section 2 reviews network reconfiguration and phase balancing algorithms, and then describes the proposed two-stage optimal network reconfiguration problem and its formulation; Section 3 demonstrates and discusses the simulation results; and Section 4 concludes the paper.

\section{Problem Formulation}

In this section, the network reconfiguration and phase balancing problems will be explained in details, and then the PSO algorithm and power flow solution technique for solving this problem will also be described; finally, a multi-objective function will be derived for the proposed two-stage approach.

\subsection{Describes Network Reconfiguration Problem}

Most distribution networks exhibit a radial configuration from the distribution substation to the customers. Sectionalizing switches and tie switches are installed in these systems to consider normal and abnormal operations. Under normal conditions, the sectionalizing switches are typically closed and the tie switches are generally open. Nevertheless, the network can be changed by performing switching actions for the best network topology to increase system performance. This process is called reconfiguration. Through network reconfiguration, power losses are reduced, load distribution becomes uniform, and overloading is avoided. System reliability is enhanced after a fault occurs.

A combinatorial problem arises because of switching actions. Therefore, when the number of switches is high, the possibility of reconfiguration increases. The most common approaches to solve this problem in network reconfiguration can be classified as follows:

- Mathematical optimization methods,

- Heuristic methods,

- Artificial intelligence methods.

These methods each have advantages and disadvantages. Based on literature reviews, these techniques can effectively address network reconfiguration problems. Solving a network 
reconfiguration problem involves two components: (1) the objective function and the system operating constraints; (2) the power flow algorithm. The common objective function is power loss minimization, and the constraints are the upper and lower limits of bus voltages, the ampere capacity of the conductor, and feasible network topology. The power flow algorithms must suit the characteristics of distribution networks with high $R / X$ ratio, short distance between two connected buses, and unbalanced load distributions and system structure.

\subsection{Describes Phase Balancing Problem}

Distribution networks are inherently unbalanced, due the single-phase three-wire, three-phase three-wire, and three-phase four-wire connections of distribution transformers widely used in distribution networks to serve various loads; besides, feeder arrangements that are not completely three-phase four-wire (three-wire), two-phase or single-phase arrangements are usually adopted in laterals or sub-laterals. Moreover, the electricity consumption of customers is random. Consequently, these factors cause the three-phase currents in a distribution feeder to be unbalanced, and then result in three-phase voltage unbalance. The voltage and current unbalances are the dominators resulting in extra power losses, increasing the current in the neutral line of three-phase four-wire distribution networks, and so on. Figure 1 shows the six connection schemes of individual phase loads for threephase buses, the individual phase loads can be derived by the integrated models of distribution transformers with theirs loads [13]; therefore, there are six possible connection schemes at the threephase bus, and similarly, two connection schemes at a two-phase bus, and one connection scheme at a single-phase bus. To improve the phase voltage and current unbalance conditions, the common approach is to derive the combinations of suitable phase connections between the individual phase load and a primary feeder; this is called phase balancing. However, electrical distribution engineers usually use the conventional trial and error approach, and it is time consuming to achieve an acceptable result; ultimately it fails to solve for the phase balancing problem. Fortunately, some effective optimal algorithms for phase balancing were proposed to improve the unbalance and to increase system operation efficiency, such as the mixed-integer programming method [14], genetic algorithm [15], phase balancing algorithm considering time-varying load patterns [16], expert systems [17], etc. According to the literature reviews, these approaches are able to effectively address phase balancing problems. The objective function, system operating constraints, and the power flow algorithm are essential to solve this problem.

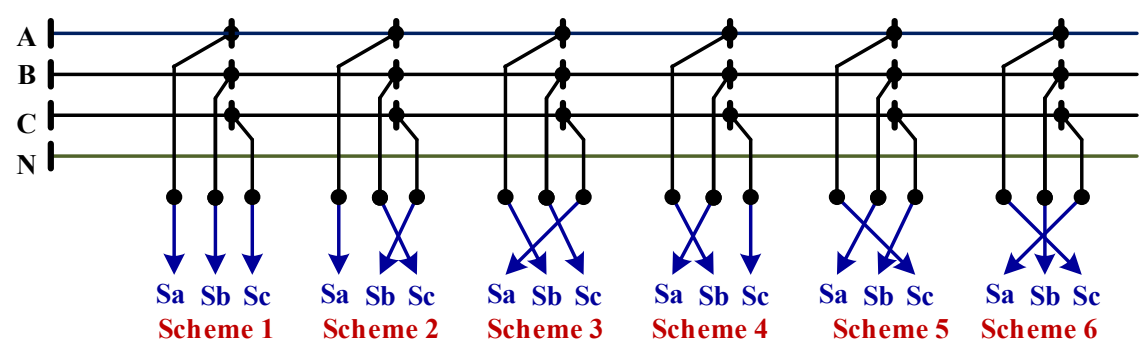

Figure 1. Six connection schemes for three-phase buses.

\subsection{Particle Swarm Optimization Algorithm}

In this paper, the PSO algorithm is used to solve the two-stage optimal network reconfiguration problem, it was introduced by Kennedy and Eberhart $[18,19]$ in 1995 . This algorithm is a populationbased optimal search technique describing certain social behaviors of animals, such as fish schooling or bird flocking. PSO simulates the population behavior that combines the cognition-only model and the social-only model, as shown in Equations (1) and (2), respectively. The cognition-only model searches for the individual best solutions as the local best (pbest) and changes particle position and velocity to move in a multi-dimensional space until the convergence constraints are reached. In the social-only model, the pbest and global best (gbest) are compared to update the gbest and change 
particle position and velocity. The combination of pbest and gbest in PSO allows the particle to adjust rapidly and correctly, which results in fast convergence using Equations (3)-(5):

$$
\begin{gathered}
V_{n}^{k+1}=V_{n}^{k}+c_{1} \times \text { rand }_{1} \times\left(\text { pbest }_{n}^{k}-s_{n}^{k}\right) \\
V_{n}^{k+1}=V_{n}^{k}+c_{2} \times \text { rand }_{2} \times\left(\text { gbest }^{k}-s_{n}^{k}\right) \\
V_{n}^{k+1}=w \times V_{n}^{k}+c_{1} \times \text { rand }_{1} \times\left(\text { pbest }_{n}^{k}-s_{n}^{k}\right)+c_{2} \times \text { rand }_{2} \times\left(\text { gbest }^{k}-s_{n}^{k}\right) \\
s_{n}^{k+1}=s_{n}^{k}+v_{n}^{k+1} \\
w=w_{\text {max }}-\left(w_{\text {max }}-w_{\min }\right) \times \frac{k}{k_{\text {max }}}
\end{gathered}
$$

where $k_{\max }$ is the maximum iteration, $n$ is the particle number, $V_{n}^{k}$ is the velocity of particle $n$ at the $k^{\text {th }}$ iteration, $s_{n}^{k}$ is the $k^{\text {th }}$ position of particle $n, c_{1}$ and $c_{2}$ are learning factors, rand 1 and rand $_{2}$ are random numbers between 0 and 1, pbest $_{n}^{k}$ is the best value of particle $n$ at the $k^{\text {th }}$ iteration, and gbest $^{k}$ is the global best value at the $k^{\text {th }}$ iteration. $w, w_{\max }$, and $w_{\min }$ are acceleration coefficients, maximum weighting values, and minimum weighting values, respectively.

\subsection{Power Flow Algorithm}

The network reconfiguration and phase balancing problems must be solved by the power flow algorithm. Two common frame of reference-based power flow algorithms are used in distribution networks: the Gauss and Newton-Raphson algorithms based on bus frame of reference are common techniques used for power flow solutions [20-24]; besides, other algorithms based on branch frame of reference were adopted for solving unbalanced power flows [25-28]. Graph theory and the backward/forward sweep method $[25,26]$ were applied in the proposed power flow algorithm. Graph theory is a systematic approach to build incidence matrices that correspond to network topologies. The incidence matrices used in the proposed algorithm is the $A$ matrix, which is the element-bus incidence matrix, and the $K$ matrix, which is branch-path incidence matrix. Based on these matrices, the bus-injection to branch-current (BIBC) matrix and the branch-current to bus-voltage (BCBV) matrix can be established according to various system structures. Furthermore, BIBC and BCBV matrices are adopted in the power flow algorithm. The power flow solution procedure is described as follows:

Step 1: Build the $A$ matrix. The $K$ matrix can be derived using Equation (6). Establish the BIBC matrix using Equation (7), as follows:

$$
\begin{gathered}
K=\left[A^{-1}\right]^{t} \\
{[\mathrm{BIBC}]=-K}
\end{gathered}
$$

Step 2: Transpose the BIBC matrix and add the primitive line impedance into the corresponding non-zero element position to derive the BCBV matrix.

Step 3: Compute the equivalent bus injection current at each bus connected to the source or load using Equation (8) as follows:

$$
I_{i}^{k}=\left(\frac{P_{i}+Q_{i}}{V_{i}^{k}}\right)^{*}
$$

Step 4: Calculate the voltage derivation of each bus using Equation (9):

$$
\left[\Delta V^{k}\right]=[B I B C][B C B V]\left[I^{k}\right]
$$

Step 5: Update the bus voltage using Equation (10), where $V_{\text {no_load }}$ is the no-load voltage at each bus, that is:

$$
\left[V^{k+1}\right]=\left[V_{\text {no } \_ \text {load }}\right]\left[\Delta V^{k}\right]
$$


Step 6: Check whether convergence is achieved using Equation (11). If convergence is not achieved, then proceed to step 3; otherwise, end the solution procedure. $\varepsilon$ is the maximum toleration, that is:

$$
\max _{i}\left(\left|I_{i}^{k+1}\right|-\left|I_{i}^{k}\right|\right)>\varepsilon
$$

\subsection{Description of the Objective Function}

Up to now, few literatures on this subject have simultaneously solved for both network reconfiguration and phase balancing problems, although some works have solved these two problems individually. It is time consuming and even more divergent to deal with them at the same time, especially for large scale systems. Consequently, in this paper, the problem is divided into two sub-problems, which are network reconfiguration and phase balancing; Figure 2 depicts the proposed two-stage optimal network reconfiguration approach. In general, due to the fact that power loss reduction by network reconfiguration is much better than phase balancing, and besides, because of the combinations of switch status are relatively less than those of phase arrangements of the loads at each bus, the network reconfiguration optimization is therefore chosen as a first stage for considerable power loss reduction, and then the power loss and voltage unbalance will be improved by phase balancing in the second stage. In order to rigidly consider the unbalanced characteristic of distribution networks, the negative and zero voltage factors and daily energy loss are included in the proposed multi-objective function, which is explained as follows.

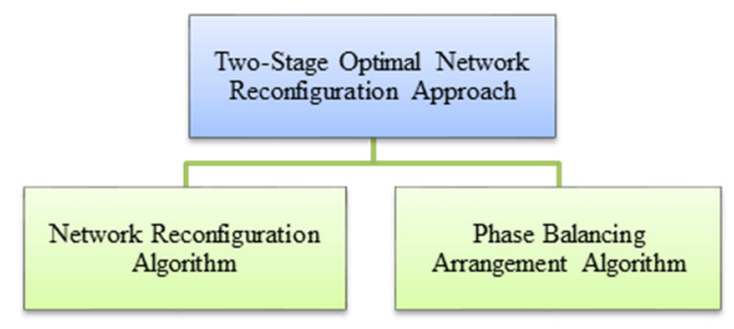

Figure 2. The schematic diagram of the proposed approach.

\subsubsection{Three-Phase Voltage Unbalance}

The zero- and negative sequence voltage factors, are defined as the zero- and negative sequence voltage component divided by the positive-sequence voltage component, respectively. Only positivesequence component exists in a three-phase balanced voltage, but otherwise the zero- and negative components exist in a three-phase unbalanced voltage. These two factors can clearly explain the extra power loss and derated operation of motors, instead of the other definitions which only consider the voltage magnitude differences between each phase. In this paper, the total zero- and negative sequence voltage factors are expressed as Equations (12) and (13), respectively:

$$
\begin{gathered}
T D_{0}=\sqrt{\frac{1}{n} \sum_{i=1}^{n}\left(\frac{\left|V_{0, i}\right|}{\left|V_{1, i}\right|}\right)^{2}} \\
T D_{2}=\sqrt{\frac{1}{n} \sum_{i=1}^{n}\left(\frac{\left|\mathrm{V}_{2, i}\right|}{\left|\mathrm{V}_{1, i}\right|}\right)^{2}}
\end{gathered}
$$

where the zero- positive- and negative sequence voltage components at bus $i$ are $V_{0, i}, V_{1, i}$ and $V_{2, i}$ and $n$ denotes the bus number.

\subsubsection{Energy Loss}

To reduce power loss is vital for increasing system operating efficiency. The ratio between the average load demand $\left(P_{\text {avg }}\right)$ and maximum load demand $\left(P_{\text {peak }}\right)$ in a period of time $(T)$ is the definition 
of load factor (LF) as shown in Equation (14), where $p(t)$ is the instantaneous power. The typical value of LF in a distribution system is between $30 \%$ and $70 \%$ [29], so the LF is set as $62.68 \%$ in this paper. The maximum load demands can be derived from the measured daily load curve. Furthermore, the loss factor (LSF) is defined as the ratio between the average power loss ( $\left.P_{\text {avg,loss }}\right)$ and maximum power loss $\left(P_{\text {peak.loss }}\right)$ in a period of time $(T)$ as shown in Equation $(15)$, where $p_{\text {loss }}(t)$ is the instantaneous power loss, and the LSF is set as $49.11 \%$ in this paper.

In this paper, the maximum load of each bus is used for power flow simulation, and the peak power loss can be computed by Equation (16); moreover, the average power loss is calculated by the peak power loss product the LSF, and thus the daily energy loss $(\mathrm{kWh})$ can be calculated by Equation (17). Once the daily energy loss is obtained, the seasonal and annual energy losses can be calculated by Equations (18) and (19), respectively.

$$
\begin{aligned}
& L F=\frac{P_{\text {avg }}}{P_{\text {paak }}} \times 100 \%=\frac{\frac{1}{T} \int_{0}^{T} p(t) \mathrm{d} t}{P_{\text {peak }}} \times 100 \% \\
& L S F=\frac{P_{\text {avg.loss }}}{P_{\text {peak, loss }}} \times 100 \%=\frac{\frac{1}{T} \int_{0}^{T} p_{\text {loss }}(t) \mathrm{d} t}{P_{\text {peak,loss }}} \times 100 \% \\
& P_{\text {peak,loss }}=\sum_{j=1}^{m} \sum_{p h \in\{a b c\}}\left|I_{\text {pakk, } j}^{p h}\right|^{2} \times R_{j}^{\text {ph }} \\
& E_{\text {daily,loss }}=P_{\text {peak,loss }} \times L S F \times 24 \times 10^{-3} \\
& E_{\text {season,loss }}=\sum_{\text {weekday } 1}^{w} E_{\text {daily,loss }}^{\text {wekday }}+\sum_{\text {holiday }=1}^{h} E_{\text {daily,loss }}^{\text {holilay }} \\
& E_{\text {annual,loss }}=\sum_{\text {season } 1}^{4} E_{\text {season,loss }}
\end{aligned}
$$

\subsubsection{Multi-Objective Function}

The goal in this paper is to minimize energy losses and improve the voltage profile in distribution networks. Consequently, the multi-objective function can be formulated as Equation (20) by combining daily energy loss and voltage unbalance factors:

$$
f=w_{1} \cdot \frac{E_{\text {daily,loss }}-E_{\text {daily,loss }}^{\min }}{E_{\text {dalily,loss }}^{\max }-E_{\text {daily,yoss }}^{\min }}+w_{2} \cdot \frac{T D_{o}-T D_{0}^{\min }}{T D_{\mathrm{o}}^{\max }-T D_{\mathrm{o}}^{\min }}+w_{3} \cdot \frac{T D_{2}-T D_{2}^{\min }}{T D_{2}^{\max }-T D_{2}^{\min }}
$$

which is subject to:

$$
\begin{gathered}
w_{1}+w_{2}+w_{3}=1 \\
P_{i+1}=P_{i}-r_{i} I_{i}^{2}-P_{L i+1} \\
Q_{i+1}=Q_{i}-x_{i} I_{i}^{2}-Q_{L i+1} \\
V_{L i} \leq V_{i} \leq V_{U i} \\
D_{0, i}=\frac{\left|V_{0, i}\right|}{\left|V_{1, i}\right|} \leq D_{0}^{\max .} \\
D_{2, i}=\frac{\left|V_{2, i}\right|}{\left|V_{1, i}\right|} \leq D_{2}^{\max .} \\
g \in G
\end{gathered}
$$

In Equation (20), because the daily energy loss and voltage unbalance factors are with distinct units and the numerical values between them are quite different, normalization of the individual item between 0 and 1 is essential for multi-objective optimization. $w_{i}$ is an adjustable weighting factor 
depend on the requirement; besides, $E_{\text {daily,oss }}^{\max }$ and $E_{\text {daily,oss }}^{\min }$ represent the maximum and minimum values of daily energy loss of the particles in a swarm; similarly, the same meanings of $T D_{0}^{\max }, T D_{0}^{\min }$, $T D_{2}^{\max }$, and $T D_{2}^{\min }$ in Equation (20).

Equations (22) and (23) represent the power balance equations in radial networks, $L$ represents the number of lines and $I_{j}$ denotes the current of the $j^{\text {th }}$ line. Meanwhile, $P_{i}$ and $Q_{i}$ denote the real and reactive power flow out of bus $i$, respectively; $r_{i}$ and $x_{i}$ are the resistance and reactance between bus $i$ and $i+1 ; L i$ represents the line current between bus $i$ and $i+1$; in Equation (24), $V_{i}, V_{U i}$, and $V_{L i}$ denote the voltage at bus $i$ and its upper and lower limits, respectively. In Equations (25) and (26), $D_{0, i}$ and $D_{2, i}$ represent the zero- and negative sequence voltage factors at bus $i$, and $D_{0}^{\max }$ and $D_{2}^{\max }$ are the specified maximum values of zero- and negative sequence voltage factors, respectively. In Equation (27), $g$ is the network topology; and $G$ represents the sets of radial topologies, which cannot be closedloop and islanding topologies, the $A$ matrix that is the element-bus incidence matrix can be used to check the network topology, if the determinant of $A$ equals 1 or -1 and then it is the radial topology; otherwise, if the determinant of $A$ equals 0 and then it is not a radial topology.

The PSO algorithm is applied to solve the proposed two-stage optimal network reconfiguration and phase balancing approach, whereby the $A$ matrix is built according to switch status and the phase connection arrangement of the load at each bus must be transferred to the PSO algorithm to have the corresponding network topology and individual complex power at each bus. The power flow algorithm is used to execute the specified network topology and then the value of the proposed function will obtained for each particle. The detailed solution procedure is illustrated in Figure 3.

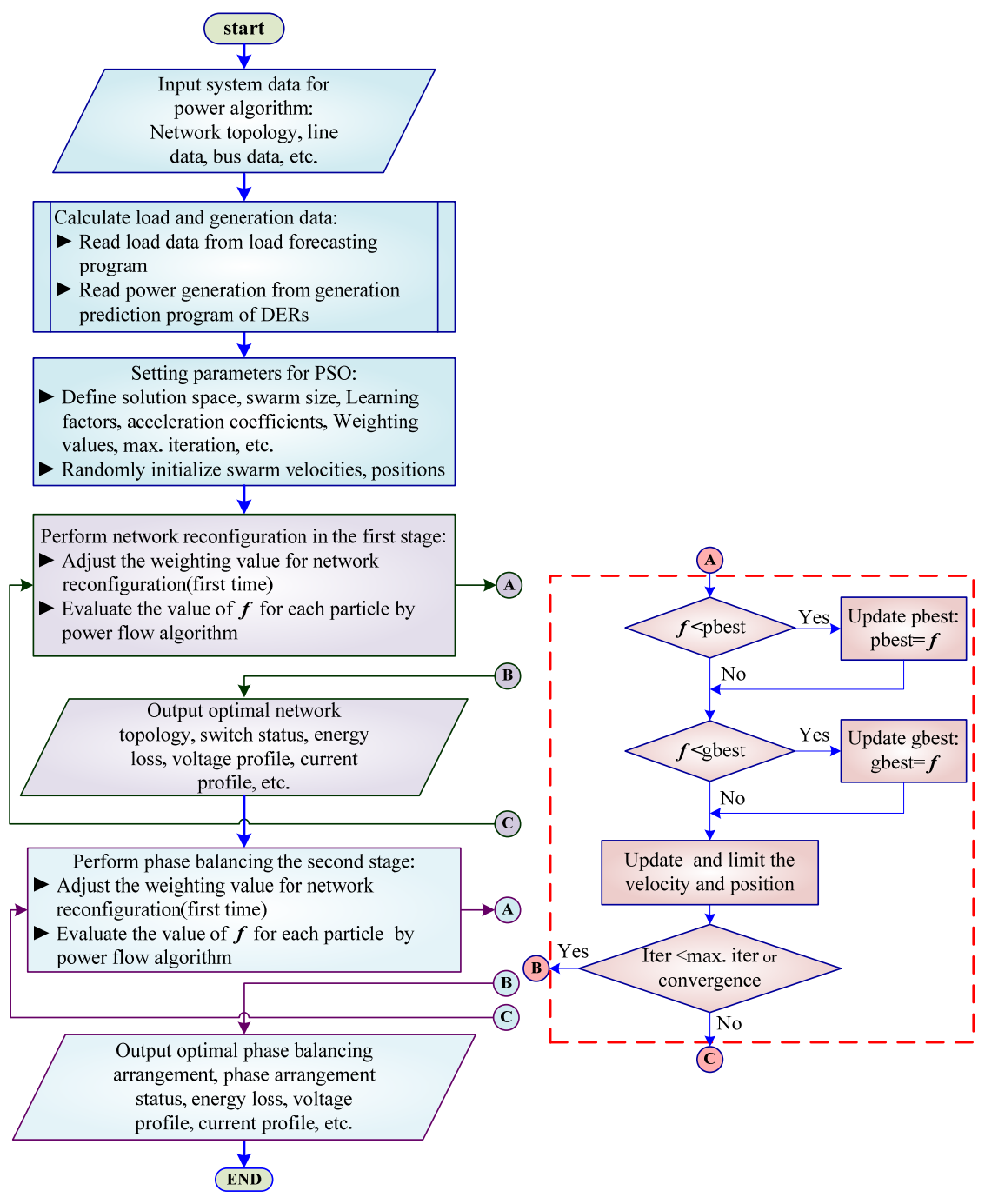

Figure 3. The flow chart of the solution procedure. 


\section{Numerical Results}

In this section, the IEEE 37-bus test system and the microgrid of the Institute of Nuclear Energy Research (INER) in Taiwan were used as sample systems to verify the effectiveness of the proposed approach. The IEEE 37-bus test system is a traditional distribution system whose line data and bus data are shown in [30]. It is a three-phase unbalance passive network that is only connected with loads. The INER microgrid is an active network with both DERs and loads. The simulation results are discussed in the following subsections.

\subsection{IEEE 37-Bus Test System}

In this case, the related parameters of PSO are shown in Table 1; besides, the individual phase loads at each bus are shown in Table 2.

Table 1. Parameters of particle swarm optimization (PSO) of IEEE 37-bus test system.

\begin{tabular}{cccccccc}
\hline \multirow{2}{*}{ Stage } & Particle & Max. iteration & $c_{1}$ & $c_{2}$ & $w_{1}$ & $w_{2}$ & $w_{3}$ \\
\cline { 2 - 8 } & 100 & 200 & 2 & 2 & 1 & 0 & 0 \\
First stage & 500 & 200 & 2 & 2 & 0.7 & 0.15 & 0.15 \\
Second stage & &
\end{tabular}

Table 2. Individual phase loads before and after phase balancing arrangement at each bus of IEEE 37bus test system.

\begin{tabular}{|c|c|c|c|c|c|c|c|}
\hline \multirow{3}{*}{$\frac{\text { Bus }}{\text { Bus number }}$} & \multirow{3}{*}{$\begin{array}{c}\text { Loads } \\
\text { Phase type }\end{array}$} & \multicolumn{6}{|c|}{ Before phase balancing } \\
\hline & & \multicolumn{2}{|c|}{ Phase A } & \multicolumn{2}{|c|}{ Phase B } & \multicolumn{2}{|c|}{ Phase C } \\
\hline & & $P(\mathrm{~kW})$ & $Q$ (kvar) & $P(\mathrm{~kW})$ & $Q$ (kvar) & $P(\mathrm{~kW})$ & $Q$ (kvar) \\
\hline 701 & $\mathrm{ABC}$ & 224.54 & 181.07 & 144.03 & 72.02 & 279.58 & 70.99 \\
\hline 712 & $\mathrm{AC}$ & 33.24 & 42.85 & 0 & 0 & 54.21 & -1.7 \\
\hline 713 & $\mathrm{AC}$ & 33.24 & 42.85 & 0 & 0 & 54.21 & -1.7 \\
\hline 714 & $\mathrm{ABC}$ & 10.84 & -0.34 & 20.07 & 8.21 & 8.18 & 10.65 \\
\hline 718 & $\mathrm{AB}$ & 54.21 & -1.7 & 33.24 & 42.85 & 0 & 0 \\
\hline 720 & $\mathrm{AC}$ & 33.24 & 42.85 & 0 & 0 & 54.21 & -1.7 \\
\hline 722 & $\mathrm{ABC}$ & 8.18 & 10.65 & 90.36 & -0.69 & 67.09 & 72.34 \\
\hline 724 & $\mathrm{BC}$ & 0 & 0 & 27.11 & -0.21 & 16.1 & 21.81 \\
\hline 725 & BC & 0 & 0 & 27.11 & -0.21 & 16.1 & 21.81 \\
\hline 727 & $\mathrm{AC}$ & 16.1 & 21.81 & 0 & 0 & 27.11 & -0.21 \\
\hline 728 & $\mathrm{ABC}$ & 42 & 21 & 42 & 21 & 42 & 21 \\
\hline 729 & $\mathrm{AB}$ & 27.11 & -0.21 & 16.1 & 21.81 & 0 & 0 \\
\hline 730 & $\mathrm{AC}$ & 33.24 & 42.85 & 0 & 0 & 54.21 & -1.7 \\
\hline 731 & BC & 0 & 0 & 54.21 & -1.7 & 33.24 & 42.85 \\
\hline 732 & $A C$ & 16.1 & 21.81 & 0 & 0 & 27.11 & -0.21 \\
\hline 733 & $\mathrm{AB}$ & 54.21 & -1.7 & 33.24 & 42.85 & 0 & 0 \\
\hline 734 & $\mathrm{AC}$ & 16.1 & 21.81 & 0 & 0 & 27.11 & -0.21 \\
\hline 735 & $A C$ & 33.24 & 42.85 & 0 & 0 & 54.21 & -1.7 \\
\hline 736 & BC & 0 & 0 & 27.11 & -0.21 & 16.1 & 21.81 \\
\hline 737 & $\mathrm{AB}$ & 90.36 & -0.68 & 53.37 & 72.7 & 0 & 0 \\
\hline 738 & $A B$ & 81.06 & -1.13 & 42.56 & 64.92 & 0 & 0 \\
\hline 740 & AC & 33.24 & 42.85 & 0 & 0 & 54.21 & -1.7 \\
\hline 741 & $\mathrm{AC}$ & 16.1 & 21.81 & 0 & 0 & 27.11 & -0.21 \\
\hline 742 & $\mathrm{ABC}$ & 5.16 & -0.04 & 57.27 & 2.45 & 33.24 & 42.85 \\
\hline 744 & $\mathrm{AB}$ & 27.11 & -0.21 & 16.1 & 21.81 & 0 & 0 \\
\hline \multicolumn{2}{|c|}{ Total } & 888.62 & 551.05 & 683.88 & 367.6 & 945.33 & 315.07 \\
\hline
\end{tabular}


Table 2. Cont.

\begin{tabular}{|c|c|c|c|c|c|c|c|}
\hline \multirow{3}{*}{$\frac{\text { Bus }}{\text { Bus number }}$} & \multirow{3}{*}{$\begin{array}{c}\text { Loads } \\
\text { Phase type }\end{array}$} & \multicolumn{6}{|c|}{ After phase balancing } \\
\hline & & \multicolumn{2}{|c|}{ Phase A } & \multicolumn{2}{|c|}{ Phase B } & \multicolumn{2}{|c|}{ Phase C } \\
\hline & & $P(\mathrm{~kW})$ & $Q$ (kvar) & $P(\mathrm{~kW})$ & $Q$ (kvar) & $P(\mathrm{~kW})$ & $Q$ (kvar) \\
\hline 701 & $\mathrm{ABC}$ & 144.03 & 72.02 & 279.58 & 70.99 & 224.54 & 181.07 \\
\hline 712 & $\mathrm{AC}$ & 33.24 & 42.85 & 0 & 0 & 54.21 & -1.7 \\
\hline 713 & $\mathrm{AC}$ & 33.24 & 42.85 & 0 & 0 & 54.21 & -1.7 \\
\hline 714 & $\mathrm{ABC}$ & 20.07 & 8.21 & 10.84 & -0.34 & 8.18 & 10.65 \\
\hline 718 & $\mathrm{AB}$ & 54.21 & -1.7 & 33.24 & 42.85 & 0 & 0 \\
\hline 720 & $\mathrm{AC}$ & 33.24 & 42.85 & 0 & 0 & 54.21 & -1.7 \\
\hline 722 & $\mathrm{ABC}$ & 8.18 & 10.65 & 67.09 & 72.34 & 90.36 & -0.69 \\
\hline 724 & $\mathrm{BC}$ & 0 & 0 & 16.1 & 21.81 & 27.11 & -0.21 \\
\hline 725 & $\mathrm{BC}$ & 0 & 0 & 27.11 & -0.21 & 16.1 & 21.81 \\
\hline 727 & $\mathrm{AC}$ & 16.1 & 21.81 & 0 & 0 & 27.11 & -0.21 \\
\hline 728 & $\mathrm{ABC}$ & 42 & 21 & 42 & 21 & 42 & 21 \\
\hline 729 & $\mathrm{AB}$ & 27.11 & -0.21 & 16.1 & 21.81 & 0 & 0 \\
\hline 730 & $A C$ & 33.24 & 42.85 & 0 & 0 & 54.21 & -1.7 \\
\hline 731 & BC & 0 & 0 & 54.21 & -1.7 & 33.24 & 42.85 \\
\hline 732 & AC & 27.11 & -0.21 & 0 & 0 & 16.1 & 21.81 \\
\hline 733 & $\mathrm{AB}$ & 33.24 & 42.85 & 54.21 & -1.7 & 0 & 0 \\
\hline 734 & AC & 16.1 & 21.81 & 0 & 0 & 27.11 & -0.21 \\
\hline 735 & $A C$ & 33.24 & 42.85 & 0 & 0 & 54.21 & -1.7 \\
\hline 736 & BC & 0 & 0 & 27.11 & -0.21 & 16.1 & 21.81 \\
\hline 737 & $A B$ & 90.36 & -0.68 & 53.37 & 72.7 & 0 & 0 \\
\hline 738 & $\mathrm{AB}$ & 81.06 & -1.13 & 42.56 & 64.92 & 0 & 0 \\
\hline 740 & $A C$ & 54.21 & -1.7 & 0 & 0 & 33.24 & 42.85 \\
\hline 741 & $\mathrm{AC}$ & 16.1 & 21.81 & 0 & 0 & 27.11 & -0.21 \\
\hline 742 & $\mathrm{ABC}$ & 57.27 & 2.45 & 33.24 & 42.85 & 5.16 & -0.04 \\
\hline 744 & $\mathrm{AB}$ & 16.1 & 21.81 & 27.11 & -0.21 & 0 & 0 \\
\hline \multicolumn{2}{|c|}{ Total } & 869.45 & 453.04 & 783.87 & 426.9 & 864.51 & 353.78 \\
\hline
\end{tabular}

Figure 4a shows the IEEE 37-bus test system with three tie switches and 33 sectionalizing switches, which are modified by the authors for this study. The simulation result of the optimal network topology that uses the proposed approach for the first stage network reconfiguration is illustrated in Figure 4b. In the figure, three tie switches between buses 701 and 722, 727 and 732, and 741 and 735 are closed and three sectionalizing switches between buses 704 and 720, 708 and 732, and 711 and 741 are opened.

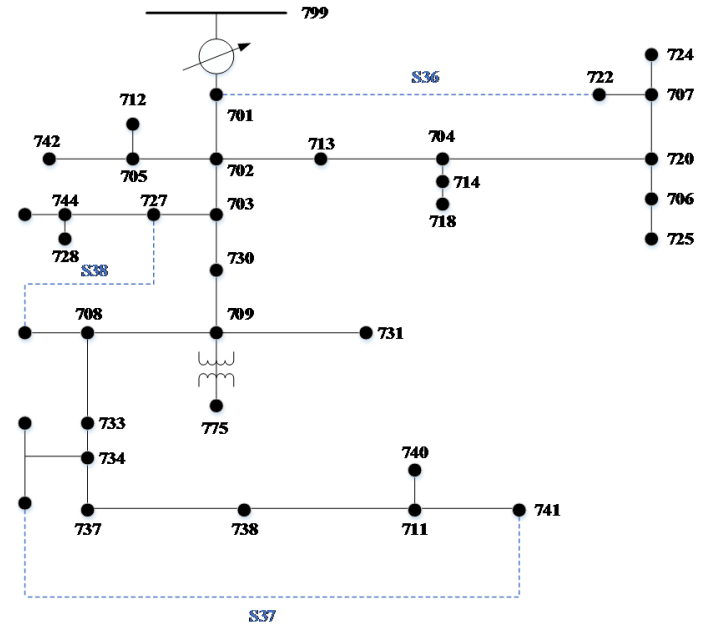

(a)

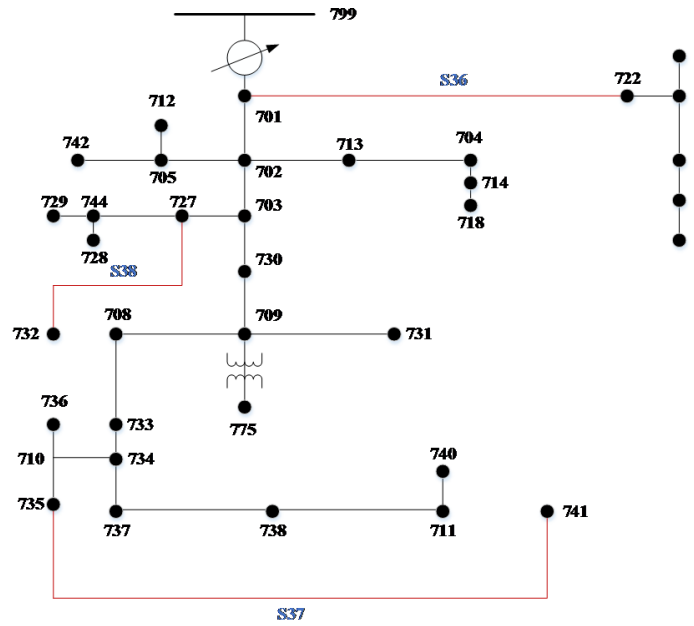

(b)

Figure 4. IEEE 37-bus test system: (a) before reconfiguration; (b) after the first stage reconfiguration. 
The trend of convergence of the proposed method of the first and second stage are shown in Figure 5a,b, respectively. The multi-objective function $f$ from initial values to the global optimum values of the first and second stage are at the $3^{\text {th }}$ and $2^{\text {th }}$ iteration, respectively. The new phase connections of individual phase loads are listed in Table 2 after second stage phase balancing algorithm, the simulation result depicts that the three-phase complex powers are more balanced than before phase arrangement.

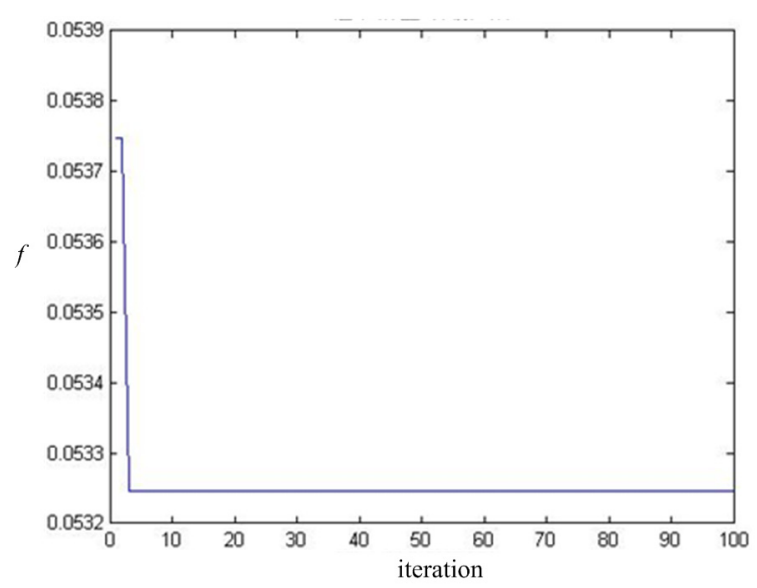

(a)

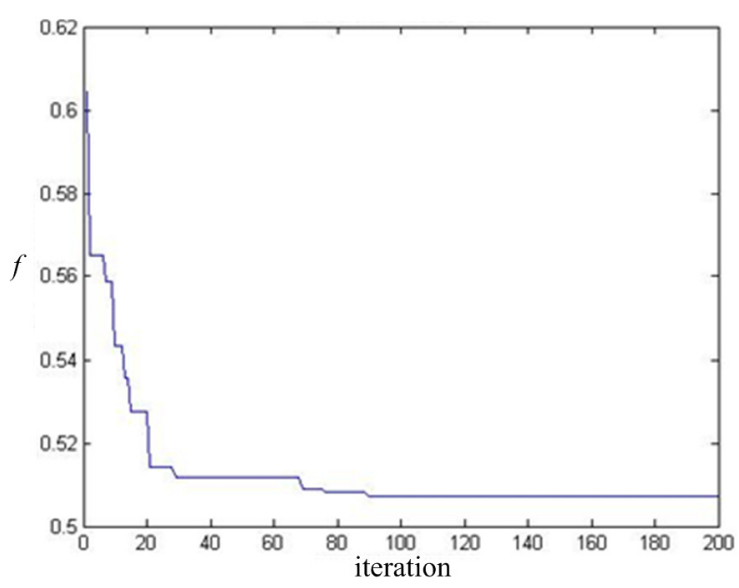

(b)

Figure 5. Convergence characteristics of proposed method of the IEEE 37-bus test system: (a) the first stage; (b) the second stage.

Figure 6 indicates the simulation result of the three-phase bus voltage profile. The voltage drop was decreased after the two-stage optimization approach; therefore, the voltage profile after optimization was better than that before optimization.

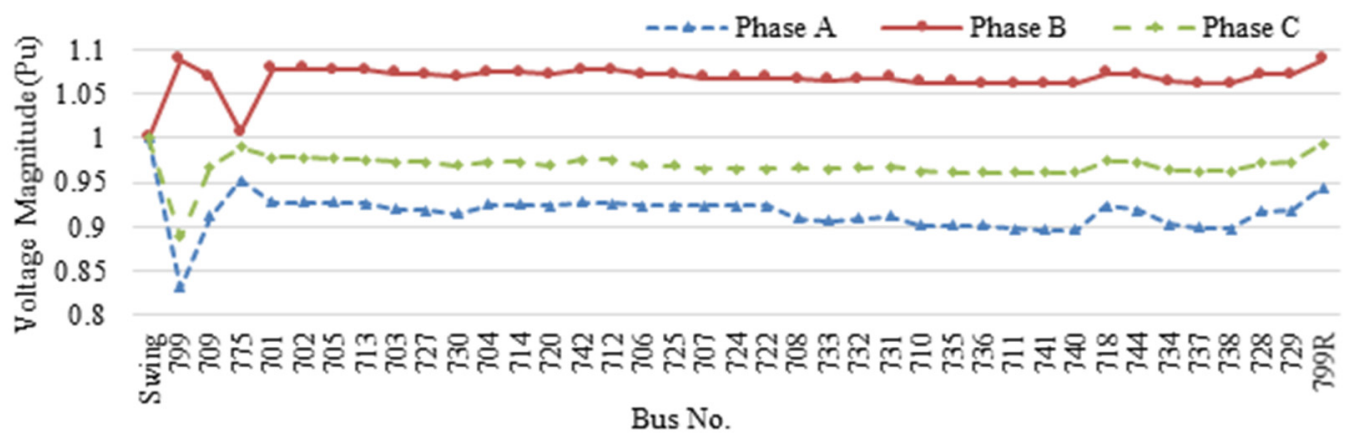

(a)

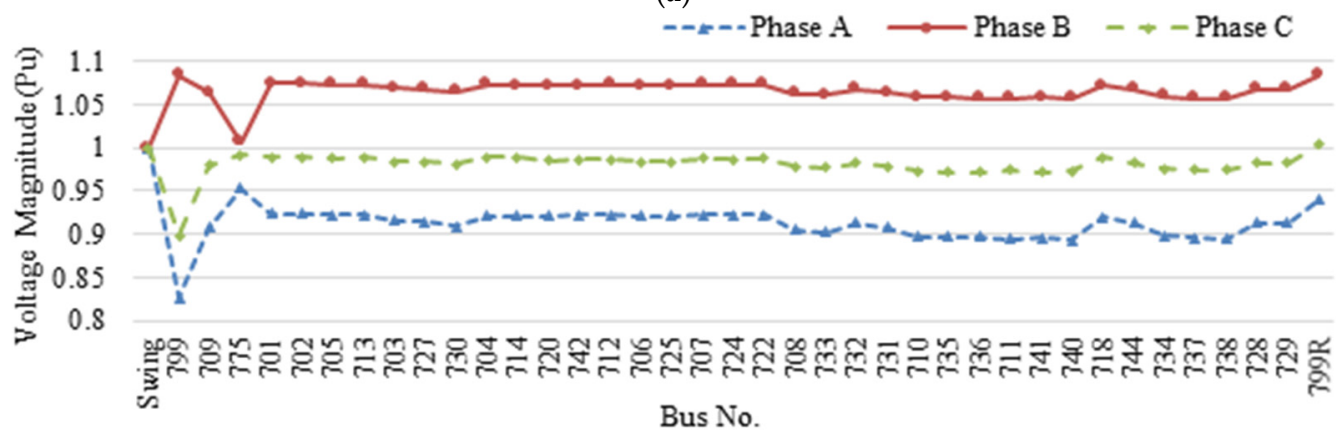

(b)

Figure 6. Cont. 


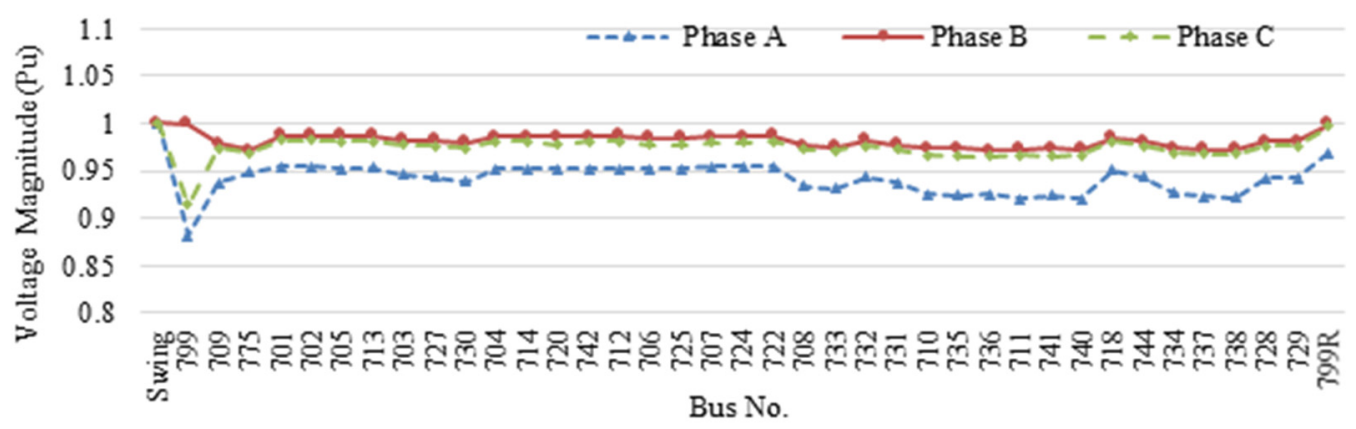

(c)

Figure 6. Simulation result of the bus voltage of the IEEE 37-bus test system: (a) before optimization; (b) after first stage; and (c) after second stage.

Moreover, Figure 7a shows that the zero-sequence voltage unbalance factor after optimization was better than that before optimization; similarly, the negative-sequence voltage unbalance factor after optimization was better than that before optimization, as shown in Figure $7 \mathrm{~b}$.

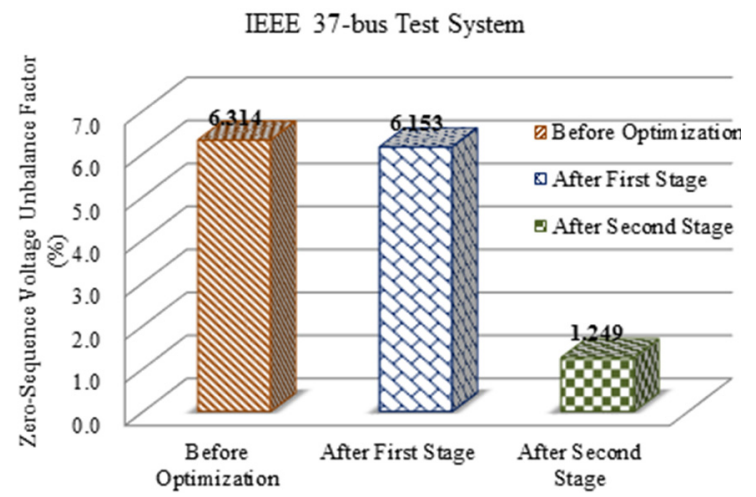

(a)
IEEE 37-bus Test System

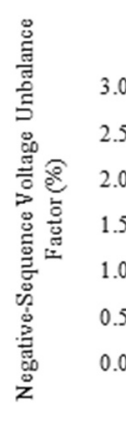

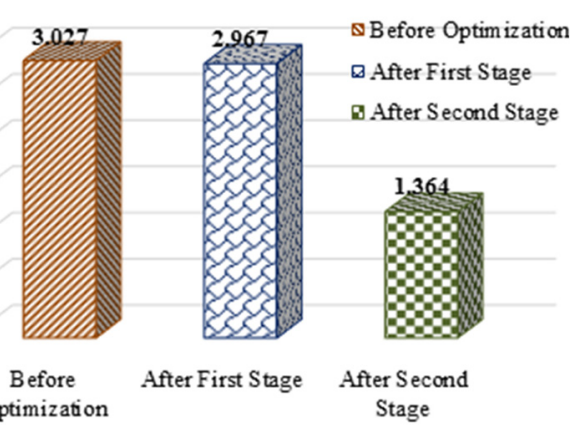

(b)

Figure 7. Simulation result of the voltage unbalance factors of the IEEE 37-bus test system: (a) zerosequence voltage unbalance factor; and (b) negative-sequence voltage unbalance factor.

In addition, the simulation results of daily energy loss before and after optimization shown in Figure 8 indicated that the daily energy loss in each line section varied because the line flow was changed and the daily energy losses were $1739 \mathrm{kWh}, 1668 \mathrm{kWh}$ and $1648 \mathrm{kWh}$, respectively. Evidently, daily energy loss was reduced after optimization. Based on these numerical results, the proposed two-stage optimal network reconfiguration approach effectively improved voltage profile, reduced energy losses, and increased operation efficiency under normal operating conditions.

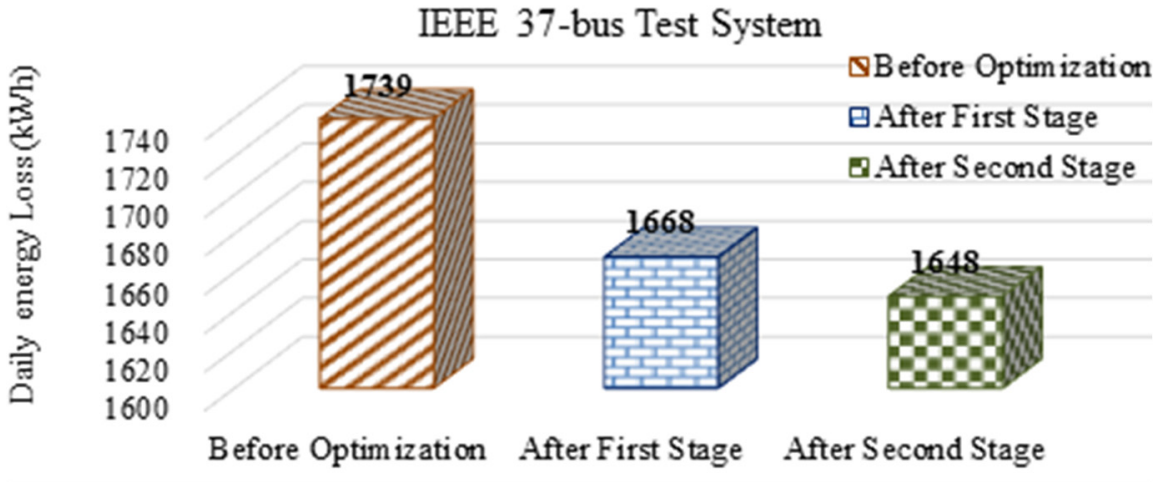

Figure 8. Simulation result of the daily energy loss of the IEEE 37-bus test system. 


\subsection{Institute of Nuclear Energy Research Microgrid}

The first outdoor microgrid test bed was developed by INER in Taiwan. This system consists of three zones with DERs and loads and includes a tie switcher and 11 sectionalizing switches, as shown in Figure 9. For example, zone 1 comprises 21 units of $1.5 \mathrm{~kW}$ high concentrator photovoltaic, one $65 \mathrm{~kW}$ microturbine unit, a $60 \mathrm{kWh}$ battery bank, and a lumped load in an office building (Building 048). The line data of the INER microgrid for the simulation is provided in Table 3. Although this is a sample network topology, the solution can be derived via a brute force search. Our proposed algorithm is a systematic approach that can be applied in a complex network topology. Thus, the effectiveness of the proposed approach can be verified using this sample system by comparing the results of the proposed approach with that of the brute force search method.

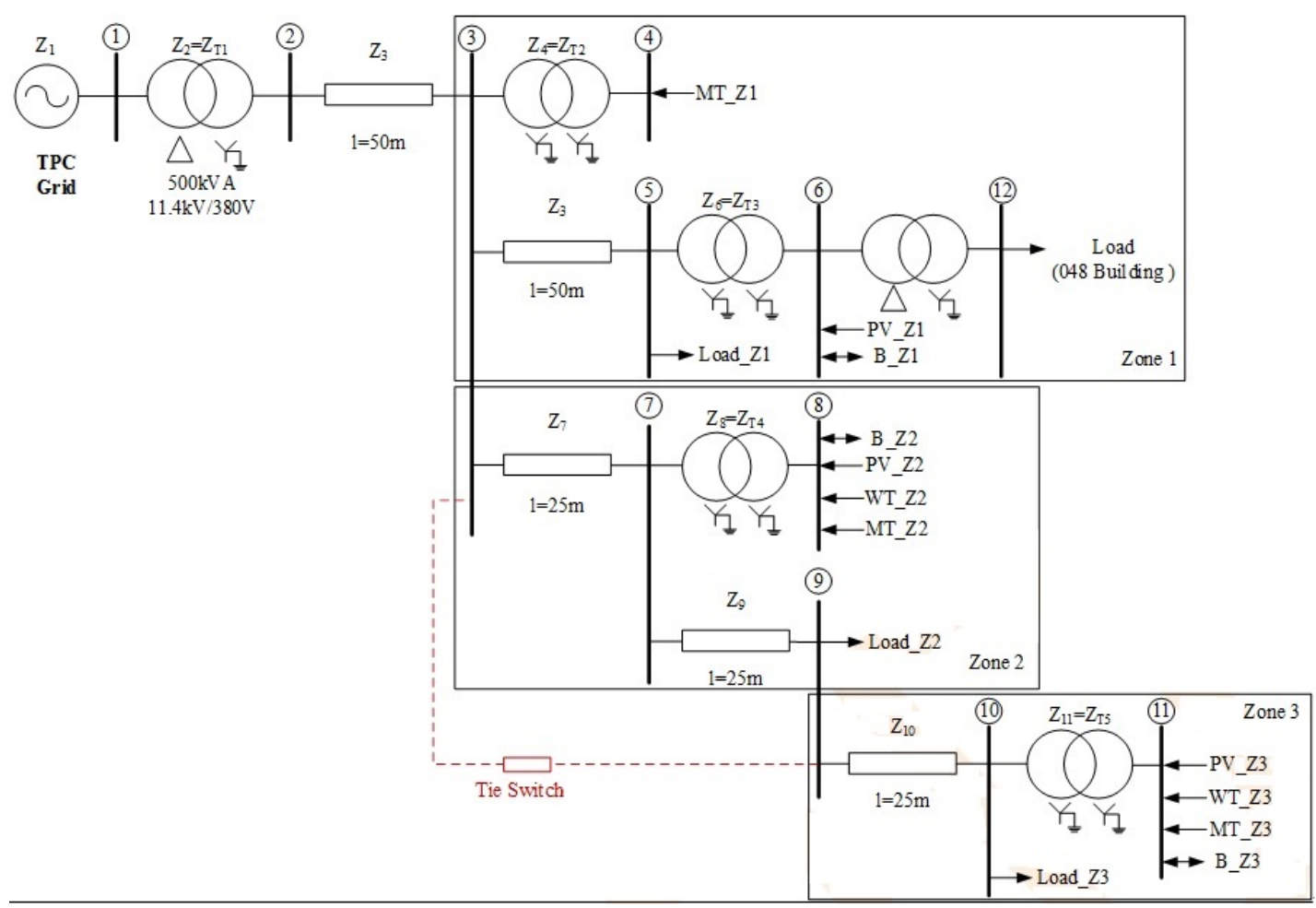

Figure 9. Single line diagram of the Institute of Nuclear Energy Research (INER) microgrid.

Table 3. Line data of the INER microgrid.

\begin{tabular}{ccccccccc}
\hline From bus & To bus & $\begin{array}{c}\text { Line resistance } \\
\mathbf{( p u )}\end{array}$ & $\begin{array}{c}\text { Line reactance } \\
\mathbf{( p u )}\end{array}$ & $\begin{array}{c}\boldsymbol{Z} \\
\mathbf{( \% )}\end{array}$ & $\begin{array}{c}\text { Distance } \\
(\mathbf{m})\end{array}$ & $\begin{array}{c}\text { Transformer } \\
\text { rating (kV) }\end{array}$ & $\begin{array}{c}\text { Transformer } \\
\text { capacity }(\mathbf{k V A})\end{array}$ & \begin{tabular}{l}
$X / R$ \\
\hline
\end{tabular} \\
\hline 1 & 2 & - & - & 3.85 & - & $11.4 / 0.38$ & 500 & 8.02 \\
2 & 3 & 0.2918 & 0.354 & - & 50 & - & - & - \\
3 & 4 & - & - & 2 & - & $0.38 / 0.48$ & 100 & 8 \\
3 & 5 & 0.2918 & 0.354 & - & 50 & - & - & - \\
5 & 6 & - & - & 4 & - & $0.38 / 0.38$ & 150 & 8 \\
3 & 7 & 0.2918 & 0.354 & - & 25 & - & - & - \\
7 & 8 & - & - & 8 & - & $0.38 / 0.38$ & 400 & 8 \\
7 & 9 & 0.2918 & 0.354 & - & 25 & - & - & - \\
9 & 10 & 0.2918 & 0.354 & - & 25 & - & - & - \\
10 & 11 & - & - & - & - & $0.38 / 0.38$ & 150 & 8 \\
3 & 9 & 0.2918 & 0.354 & - & 25 & 0 & - & - \\
6 & 12 & - & - & 4 & - & $0.38 / 0.208$ & 150 & 8 \\
\hline
\end{tabular}

Figure 10 illustrates the proposed approach applying in the optimal network reconfiguration function in EMS of the INER microgrid. In this case, the related parameters of PSO are similar to those of the IEEE 37-bus, and the differences are the particle number is 50 , and the maximum iteration is 
100; besides, the individual phase loads at each bus of a weekday in summer are shown in Table 4 . The simulation result indicated that the tie switcher was closed and a sectionalizing switcher between buses 3 and 7 was opened. This outcome is the same as that in the brute force search method. The convergence speed is very fast due to the small number of combinations; the multi-objective function $f$ of the two stages is convergent at the $20^{\text {th }}$ and $21^{\text {th }}$ iteration, respectively. The new phase connections of individual phase loads are shown in Table 4; the simulation result demonstrates that the threephase complex powers are more balanced than before phase arrangement. Figure 11 shows the simulation result of the three-phase bus voltage profile of a weekday in summer. After the two-stage optimization approach, the voltage profile was better than that before optimization. Figure 12 indicates the simulation result of the voltage unbalance factors after optimization was better than that before optimization.

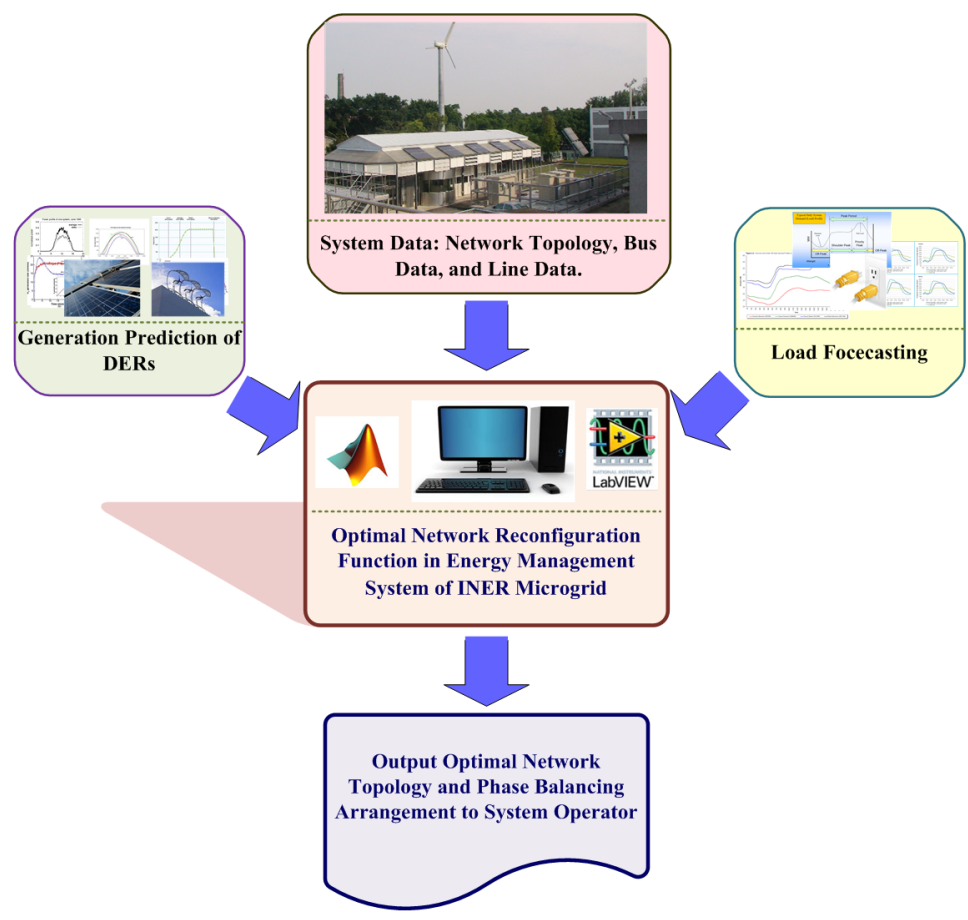

Figure 10. Optimal network reconfiguration function in energy management system (EMS) of the INER microgrid.

Table 4. Individual phase loads of a weekday in summer before and after phase balancing at each bus of the INER microgrid.

\begin{tabular}{|c|c|c|c|c|c|c|c|}
\hline \multirow{3}{*}{$\frac{\text { Bus }}{\text { Bus number }}$} & \multirow{3}{*}{$\begin{array}{c}\text { Loads } \\
\text { Phase type }\end{array}$} & \multicolumn{6}{|c|}{ Before phase balancing } \\
\hline & & \multicolumn{2}{|c|}{ Phase A } & \multicolumn{2}{|c|}{ Phase B } & \multicolumn{2}{|c|}{ Phase C } \\
\hline & & $P(\mathrm{~kW})$ & $Q$ (kvar) & $P(\mathrm{~kW})$ & $Q$ (kvar) & $P(\mathrm{~kW})$ & $Q$ (kvar) \\
\hline 2 & $\mathrm{ABC}$ & 0.5342 & 0.3106 & 0.5342 & 0.3106 & 0.5342 & 0.3106 \\
\hline 3 & $\mathrm{ABC}$ & 0.0694 & 0.0404 & 0.0694 & 0.0404 & 0.0694 & 0.0404 \\
\hline 5 & $\mathrm{ABC}$ & 24 & 4 & 19.8 & 3.3 & 16.2 & 2.7 \\
\hline 6 & $\mathrm{ABC}$ & -18.5647 & 0.0932 & -18.5647 & 0.0932 & -18.5647 & 0.0932 \\
\hline 7 & $\mathrm{ABC}$ & 0.4274 & 0.2485 & 0.4274 & 0.2485 & 0.4274 & 0.2485 \\
\hline 8 & $\mathrm{ABC}$ & -6.5333 & 0 & -6.5333 & 0 & -6.5333 & 0 \\
\hline 9 & $\mathrm{ABC}$ & 24 & 0 & 19.8 & 0 & 16.2 & 0 \\
\hline 10 & $\mathrm{ABC}$ & 12.1603 & 2.0932 & 10.0603 & 1.7432 & 8.2603 & 1.4432 \\
\hline 11 & $\mathrm{ABC}$ & -3.2667 & 0 & -3.2667 & 0 & -3.2667 & 0 \\
\hline 12 & $\mathrm{ABC}$ & 14.5001 & 0.1118 & 11.9626 & 0.0922 & 9.7876 & 0.0755 \\
\hline \multicolumn{2}{|c|}{ Total } & 47.3267 & 6.8977 & 34.2892 & 5.8281 & 23.1142 & 4.9114 \\
\hline
\end{tabular}


Table 4. Cont.

\begin{tabular}{cccccccc}
\hline \multirow{2}{*}{ Bus } & \multirow{2}{*}{ Loads } & \multicolumn{7}{c}{ After phase balancing } \\
\cline { 3 - 8 } & & \multicolumn{2}{c}{ Phase A } & \multicolumn{7}{c}{ Phase B } & \multicolumn{2}{c}{ Phase C } \\
\hline Bus number & Phase type & $P(\mathrm{~kW})$ & $Q(\mathrm{kvar})$ & $P(\mathrm{~kW})$ & $Q(\mathrm{kvar})$ & $P(\mathrm{~kW})$ & $Q(\mathrm{kvar})$ \\
2 & $\mathrm{ABC}$ & 0.5342 & 0.3106 & 0.5342 & 0.3106 & 0.5342 & 0.3106 \\
3 & $\mathrm{ABC}$ & 0.0694 & 0.0404 & 0.0694 & 0.0404 & 0.0694 & 0.0404 \\
5 & $\mathrm{ABC}$ & $\mathbf{1 9 . 8}$ & $\mathbf{3 . 3}$ & $\mathbf{2 4}$ & $\mathbf{4}$ & $\mathbf{1 6 . 2}$ & $\mathbf{2 . 7}$ \\
6 & $\mathrm{ABC}$ & -18.5647 & 0.0932 & -18.5647 & 0.0932 & -18.5647 & 0.0932 \\
7 & $\mathrm{ABC}$ & 0.4274 & 0.2485 & 0.4274 & 0.2485 & 0.4274 & 0.2485 \\
8 & $\mathrm{ABC}$ & -6.5333 & 0 & -6.5333 & 0 & -6.5333 & 0 \\
9 & $\mathrm{ABC}$ & $\mathbf{1 9 . 8}$ & $\mathbf{0}$ & $\mathbf{1 6 . 2}$ & $\mathbf{0}$ & $\mathbf{2 4}$ & $\mathbf{0}$ \\
10 & $\mathrm{ABC}$ & $\mathbf{1 0 . 0 6 0 3}$ & $\mathbf{1 . 7 4 3 2}$ & $\mathbf{1 2 . 1 6 0 3}$ & $\mathbf{2 . 0 9 3 2}$ & $\mathbf{8 . 2 6 0 3}$ & $\mathbf{1 . 4 4 3 2}$ \\
11 & $\mathrm{ABC}$ & -3.2667 & 0 & -3.2667 & 0 & -3.2667 & 0 \\
12 & $\mathrm{ABC}$ & 14.5001 & 0.1118 & 9.7876 & 0.0755 & 11.9626 & 0.0922 \\
\hline \multicolumn{7}{c}{ Total } \\
\cline { 2 - 7 }
\end{tabular}

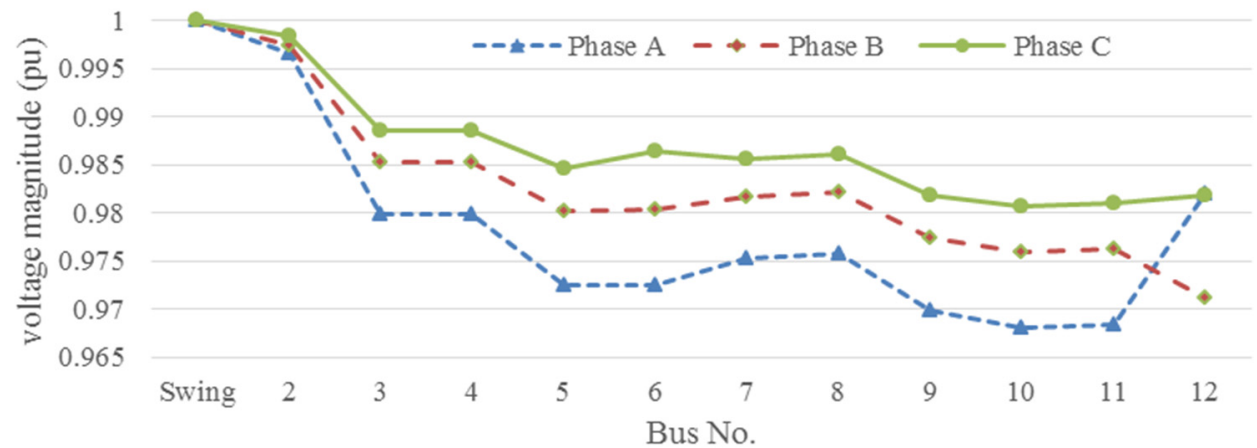

(a)

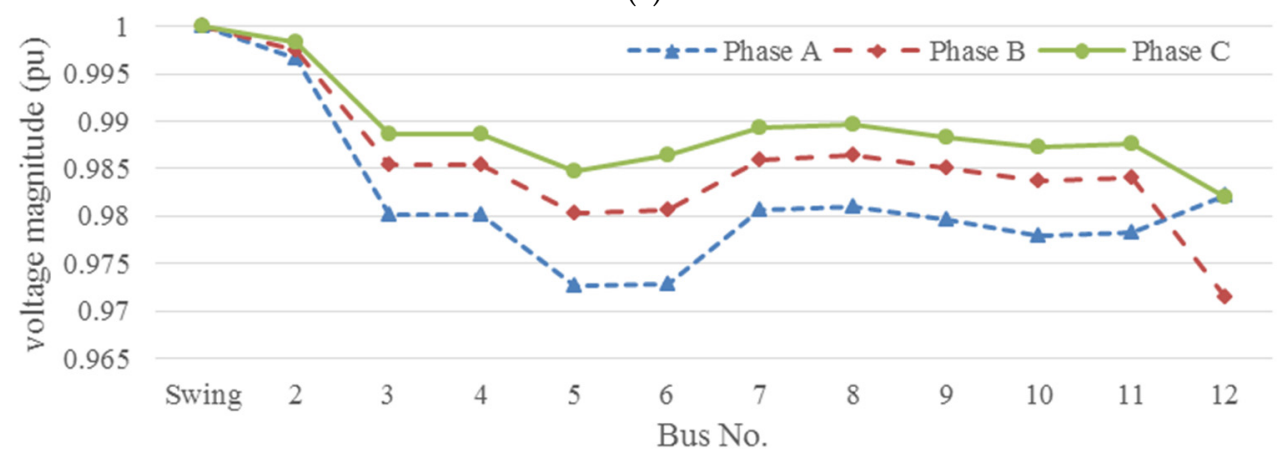

(b)

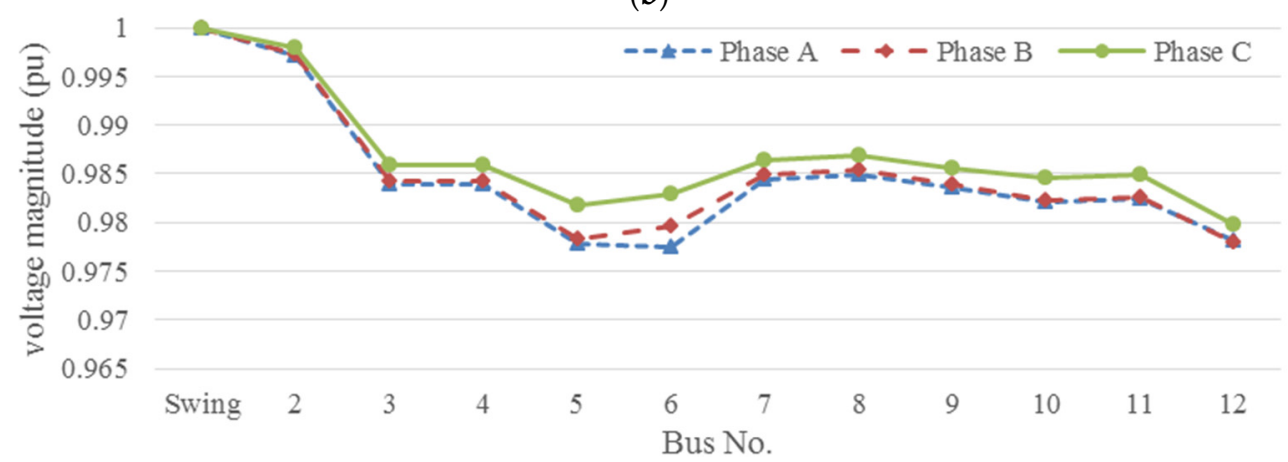

(c)

Figure 11. Simulation result of the bus voltage of a weekday in summer of the INER microgrid: (a) before optimization; (b) after first stage; and (c) after second stage. 


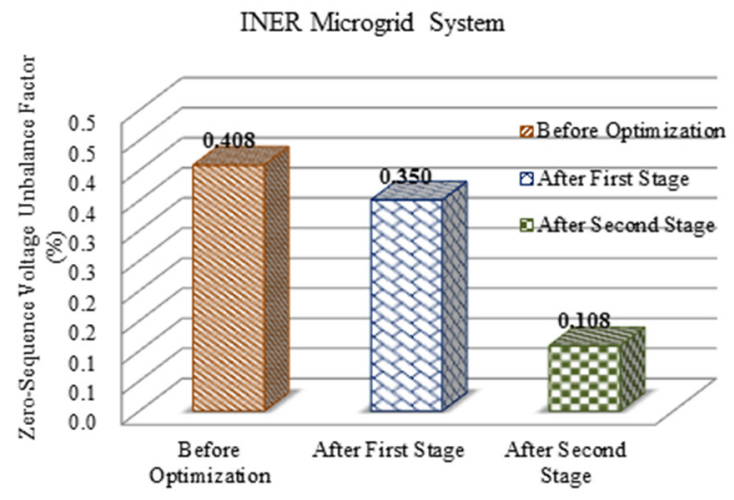

(a)

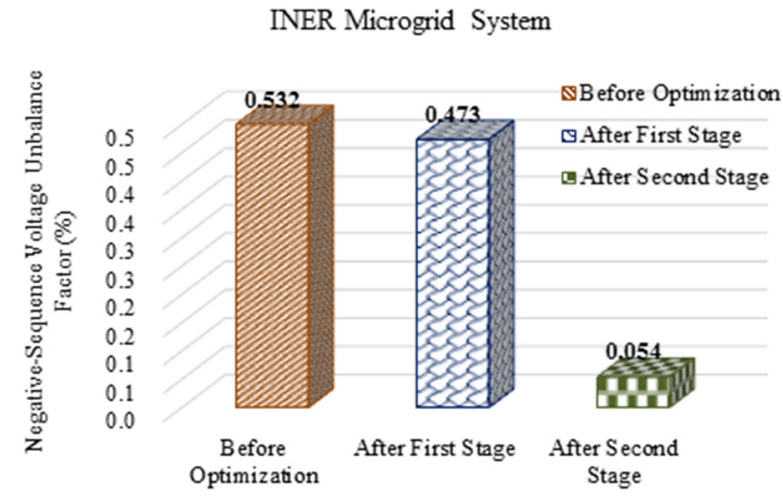

(b)

Figure 12. Simulation result of the Voltage Unbalance Factors of a weekday in summer of the INER microgrid: (a) zero-sequence voltage unbalance factor; (b) negative-sequence voltage unbalance factor.

Furthermore, the daily energy losses of the four seasons are all reduced after reconfiguration as shown in Figure 13. Based on the numerical results, the proposed algorithm was proven to be a feasible approach to improve voltage quality, reduce energy loss, and increase efficiency under normal operating conditions.

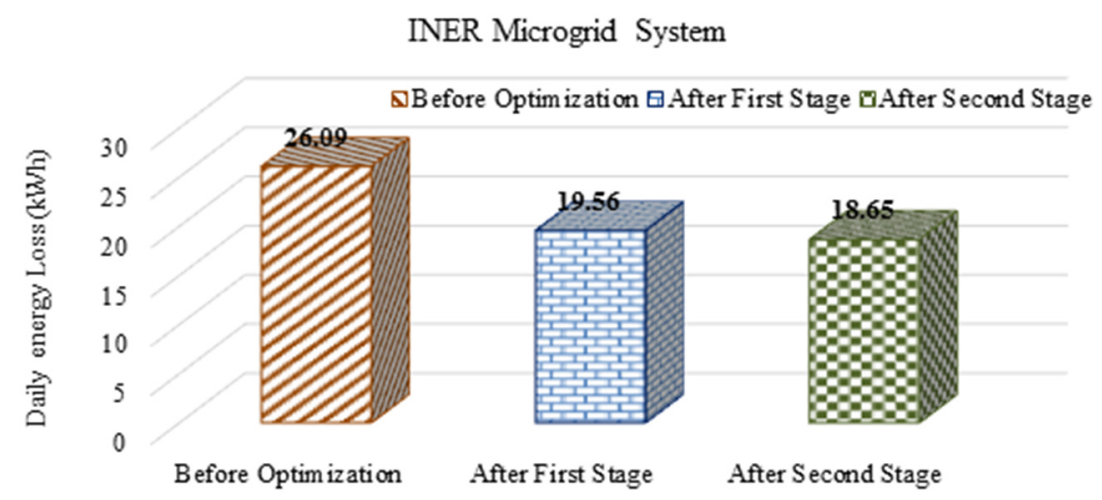

Figure 13. Simulation result of the daily energy loss of a weekday in summer of the INER microgrid.

\section{Conclusions}

A two-stage optimal approach, which is composed of network reconfiguration and phase balancing algorithms that applies a graph theory-based power flow solution technique, has been developed in this study. PSO exhibits self-learning capability to obtain the most optimal solution, and the graph theory-based power flow algorithm can easily establish the network topology using incidence matrices according to different system structures. The IEEE 37-bus system and the INER microgrid have been used as sample systems to verify the effectiveness of the proposed approach. The numerical results demonstrate that this approach can improve voltage profiles, reduce energy losses, and increase efficiency under normal operating conditions. The developed algorithm can be applied in traditional distribution networks with or without DERs and microgrids to improve system operation performance.

Acknowledgments: The authors are grateful for financial support from the Ministry of Science and Technology, Taiwan, under Grant MOST 104-3113-E-042A-004-CC2.

Author Contributions: The paper was a collaborative effort between the authors. All authors have read and approved the final manuscript.

Conflicts of Interest: The authors declare no conflict of interest. 


\section{References}

1. Lasseter, R.H.; Asano, H.; Iravani, R.; Marnay, C. Microgrids. IEEE Power Energy Mag. 2007, 5, 78-94.

2. Lasseter, R.H. Smart distribution: Coupled microgrids. IEEE Power Energy Mag. 2011, 99, 1074-1082.

3. Hong, Y.-Y.; Lai, Y.-M.; Chang, Y.-R.; Lee, Y.-D.; Liu, P.-W. Optimizing Capacities of Distributed Generation and Energy Storage in a Small Autonomous Power System Considering Uncertainty in Renewables. Energies 2015, 8, 2473-2492.

4. Huang, W.-T.; Yao, K.-C.; Wu, C.-C. Using the Direct Search Method for Optimal Dispatch of Distributed Generation in a Medium-Voltage Microgrid. Energies 2014, 7, 8355-8373.

5. Kim, H.-M.; Lim, Y.; Kinoshita, T. An intelligent multiagent system for autonomous microgrid operation. Energies 2012, 5, 3347-3362.

6. Kim, H.-M.; Kinoshita, T.; Shin, M.-C. A multiagent system for autonomous operation of islanded microgrids based on a power market environment. Energies 2010, 3, 1972-1990.

7. Yoo, C.-H.; Chung, I.-Y.; Lee, H.-J.; Hong, S.-S. Intelligent control of battery energy storage for multi-agent based microgrid energy management. Energies 2013, 6, 4956-4979.

8. Merlin, A.; Back, H. Search for a minimal-loss operating spanning tree configuration in an urban power distribution system. In Proceedings of the 5th Power System Computation Conference (PSCC), Cambridge, UK, 1-5 September 1975; pp. 1-18.

9. Civanlar, S.; Grainger, J.J.; Yin, H.; Lee, S.S.H. Distribution reconfiguration for loss reduction. IEEE Trans. Power Deliv. 1988, 3, 1217-1223.

10. Jeon, Y.J.; Kim, J.C.; Kim, J.O.; Shin, J.R.; Lee, K.Y. An efficient simulated annealing algorithm for network reconfiguration in large-scale distribution systems. IEEE Trans. Power Deliv. 2002, 17, 1070-1078.

11. Venkatesh, B.; Ranjan, R. Optimal radial distribution system reconfiguration using fuzzy adaptation of evolutionary programming. Int. J. Electr. Power Energy Syst. 2003, 25, 775-780.

12. Hamdoui, H.; Hadjeri, S.; Zeblah, A. A new constructive method for electric power system reconfiguration using ant colony. Leonardo Electron. J. Pract. Tech. 2008, 12, 49-60.

13. Chen, T.H.; Chang, Y.L. Integrated Models of Distribution Transformers and Their Loads for Three-phase Power Flow Analyses. IEEE Trans. Power Deliv. 1996, 11, 507-513.

14. Zhu, J.; Chow, M.Y.; Zhang, G.F. Phase balancing using mixed-integer programming. IEEE Trans. Power Syst. 1998, 13, 1487-1492.

15. Chen, T.H.; Cherng, J.T. Optimal phase arrangement of distribution transformers connected a primary feeder for system unbalance improvement and loss reduction using a genetic algorithm. IEEE Trans. Power Syst. 2000, 15, 994-1000.

16. Murat, D.; Robot, P.B.; Jeferey, C.T.; Richard, S. Simultaneous Phase Balancing at Substations and Switches with Time-Varying Load Patterns. IEEE Trans. Power Syst. 2001, 16, 922-928.

17. Lin, C.H.; Chen, C.S.; Chuang, H.J. An Expert System for Three-Phase Balancing of Distribution Feeders. IEEE Trans. Power Syst. 2008, 23, 1488-1496.

18. Kennedy, J.; Eberhart, R.C. Particle swarm optimization. In Proceedings of the IEEE International Conference on Neural Networks, Perth, Australia, 27 November-1 December 1995; Volume 4, pp. 1942-1948.

19. Eberhart, R.C.; Kennedy, J. A new optimizer using particle swarm theory. In Proceedings of the IEEE International Symposium on Micro Machine and Human Science, Nagoya, Japan, 4-6 October 1995; pp. 39-43.

20. Chen, T.H.; Chen, M.S.; Inoue, T.; Kotas, P.; Chebli, E.A. Three-phase cogenerator and transformer models for distribution system analysis. IEEE Trans. Power Deliv. 1991, 6, 1671-1681.

21. Vieira, J.C.M.; Freitas, W.; Morelato, A. Phase-decoupled method for three-phase power-flow analysis of unbalanced distribution systems. IEE Proc. Gener. Transm. Distrib. 2004, 151, 568-574.

22. Marinho, J.M.T.; Taranto, G. A Hybrid Three-Phase Single-Phase Power Flow Formulation. IEEE Trans. Power Syst. 2008, 23, 1063-1070.

23. Kersting, W.H. Radial distribution test feeders. IEEE Trans. Power Syst. 1991, 6, 975-985.

24. Dugan, R.C.; Santoso, S. An example of 3-phase transformer modeling for distribution system analysis. In Proceedings of the IEEE PES Transmission Distribution Conference and Exposition, Dallas, TX, USA, 7-12 September 2003; Volume 3, pp. 1028-1032.

25. Chen, T.H.; Yang, N.C. Three-phase power-flow by direct ZBR method for unbalanced radial distribution systems. IET Gener. Transm. Distrib. 2009, 3, 903-910. 
26. Teng, J.H. A network-topology based three: Phase load flow for distribution systems. Proc. Natl. Sci. Counc. ROC A Phys. Sci. Eng. 2000, 24, 259-264.

27. Teng, J.H. A direct approach for distribution system load flow solution. IEEE Trans. Power Deliv. 2003, 18, 882-887.

28. Elsaiah, S.; Benidris, M.; Mitra, J. A three-phase power flow solution method for unbalanced distribution networks. In Proceedings of the North American Power Symposium, Boston, MA, USA, 4-6 August 2011; pp. 1-8.

29. Oliveira, M.E.; Boson, D.F.A.; Padilha-Feltrin, A. A statistical analysis of loss factor to determine the energy losses. In Proceedings of the IEEE/PES Transmission and Distribution Conference and Exposition, Bogota, Colombia, 13-15 August 2008; pp. 1-6.

30. Distribution Test Feeders. Available online: http://ewh.ieee.org/soc/pes/dsacom/testfeeders/index.html (accessed on 5 October 2015).

(C) 2015 by the authors; licensee MDPI, Basel, Switzerland. This article is an open access article distributed under the terms and conditions of the Creative Commons by Attribution (CC-BY) license (http://creativecommons.org/licenses/by/4.0/). 